\title{
Review Article \\ Recent Advances in Energy Harvesting Technologies for Structural Health Monitoring Applications
}

\author{
Joseph Davidson and Changki Mo \\ School of Mechanical and Materials Engineering, Washington State University Tri-Cities, 2710 Crimson Way, Richland, \\ WA 99354, USA \\ Correspondence should be addressed to Changki Mo; changki.mo@tricity.wsu.edu
}

Received 23 September 2013; Revised 31 January 2014; Accepted 1 February 2014; Published 13 April 2014

Academic Editor: Hideki Hosoda

Copyright (C) 2014 J. Davidson and C. Mo. This is an open access article distributed under the Creative Commons Attribution License, which permits unrestricted use, distribution, and reproduction in any medium, provided the original work is properly cited.

\begin{abstract}
This paper reviews recent developments in energy harvesting technologies for structural health monitoring applications. Many industries have a great deal of interest in obtaining technology that can be used to monitor the health of machinery and structures. In particular, the need for autonomous monitoring of structures has been ever-increasing in recent years. Autonomous SHM systems typically include embedded sensors, data acquisition, wireless communication, and energy harvesting systems. Among all of these components, this paper focuses on the energy harvesting technologies. Since low-power sensors and wireless communications are used in newer SHM systems, a number of researchers have recently investigated techniques to extract energy from the local environment to power these stand-alone systems. Ambient energy sources include vibration, thermal gradients, solar, wind, pressure, etc. If the structure has a rich enough loading, then it may be possible to extract the needed power directly from the structure itself. Harvesting energy using piezoelectric materials by converting applied stress to electricity is most common. Other methods to harvest energy such as electromagnetic, magnetostrictive, or thermoelectric generator are also reviewed. Lastly, an energy harvester with frequency tuning capability is demonstrated.
\end{abstract}

\section{Introduction}

Rapid advances in wireless technologies and low-power electronics have enabled the increased use of autonomous systems for the monitoring of structural health. The use of wireless structural health monitoring (SHM) systems presents several advantages, one of the most significant being that wireless systems can provide continuous monitoring without the associated installation costs of wiring, which, depending upon the size of the sensor network, can be prohibitive. Because many wireless sensor nodes are powered by traditional batteries that must be replaced, recent research has focused on developing systems that can be powered by harvesting ambient energy, such as mechanical vibrations, solar, and wind, directly from their environments. Park et al. [1] reviewed developments in energy harvesting technologies for SHM sensor systems prior to 2007. In addition to discussing methods of energy harvesting, the system design considerations, sensor modalities, network strategies, and dynamic power requirements of SHM sensor systems were also considered.

This paper reviews developments from 2008 to 2013 in the methods of energy harvesting for the powering of wireless SHM systems. This paper is not intended to provide an exhaustive literature survey, as the area of energy harvesting is very broad and most energy harvesting technologies have some applicability for SHM. Rather, this paper serves as a concise introductory survey of recent energy harvesting research related to the SHM of machinery, civil, and aerospace applications. The focus of the paper is the method of energy harvesting, though many of the references reviewed also discuss other design considerations like power management, sensor network implementation, and so forth. The specific energy sources considered include ambient mechanical vibrations, wind and aeroelastic vibrations, rotational kinetic energy, thermal energy, and solar energy. These are some of the most frequently exploited energy sources, and a broad survey of their typical power densities has already 
TABLE 1: Comparison of energy harvesting methods [15].

\begin{tabular}{|c|c|c|}
\hline & $\begin{array}{c}\text { Power density }\left(\mu \mathrm{W} / \mathrm{cm}^{3}\right) \\
\text { 1-year lifetime }\end{array}$ & $\begin{array}{c}\text { Power density }\left(\mu \mathrm{W} / \mathrm{cm}^{3}\right) \\
10 \text {-year lifetime }\end{array}$ \\
\hline Solar (outdoors) & $\begin{array}{l}\text { 15,000-direct sun } \\
150 \text {-cloudy day }\end{array}$ & $\begin{array}{l}\text { 15,000-direct sun } \\
150 \text { - cloudy day }\end{array}$ \\
\hline Solar (indoors) & 6-office desk & 6-office desk \\
\hline Vibrations & 200 & 200 \\
\hline Temperature gradient & $15 @ 10^{\circ} \mathrm{C}$ gradient & $15 @ 10^{\circ} \mathrm{C}$ gradient \\
\hline Batteries (nonrecharg. lithium) & 45 & 3.5 \\
\hline
\end{tabular}

been completed by Roundy [15]. The results of this survey are shown in Table 1.

As much of the current research is focused on the field of nonlinear energy harvesting, recent advances in this area are also reviewed. Lastly, to highlight some of the advantages of tunable energy harvesters the authors present some of their own experimental results for a piezoelectric cantilever energy harvester with frequency tuning capability designed for the monitoring of an industrial ventilation system.

\section{Sources of Energy}

2.1. Ambient Mechanical Vibrations. Mechanical vibration is a source of ambient energy commonly converted into usable electrical energy. Typically, the electrical energy is generated by using vibrations present in the environment or surrounding system to apply strain energy to a piezoelectric material, which becomes electrically polarized when subjected to strain, or to displace an electromagnetic coil. Piezoelectric materials form transducers that couple electrical energy and mechanical force. When a piezoelectric material is subjected to a mechanical stress, an electrical charge is produced across the material, and when a voltage is applied, a strain develops in the piezoelectric material.

The method and results of a study involving the development and demonstration of a wireless measurement system for use in the diagnosis of the state of a rotating machinery system were presented by Clark et al. [2]. Figure 1 shows the driving motor with the energy harvesting devices attached. The energy harvesting devices are excited by the vibration of the motor itself. The complete system includes an integrated circuit that acquires data from sensors, transmits that data wirelessly to a receiver, and manages the flow of energy into and out of a battery which powers all of these operations and is connected to the piezoelectric harvester. The results of a typical data acquisition and transmission test, which measures the $3300 \mu \mathrm{F}$ storage capacitor voltage versus time, show that initially the capacitor starts with almost no charge. In this particular test the capacitor voltage increases as energy is acquired from the harvester up to a steady-state level of approximately $6 \mathrm{~V}$. The sensor "sample and transmit" period for the test was approximately 10 minutes [2].

The powering of sensors for damage detection in machinery is a common application of energy harvesting technology. Arms et al. [3] developed an energy harvesting wireless sensor in order to track the load history of rotating helicopter

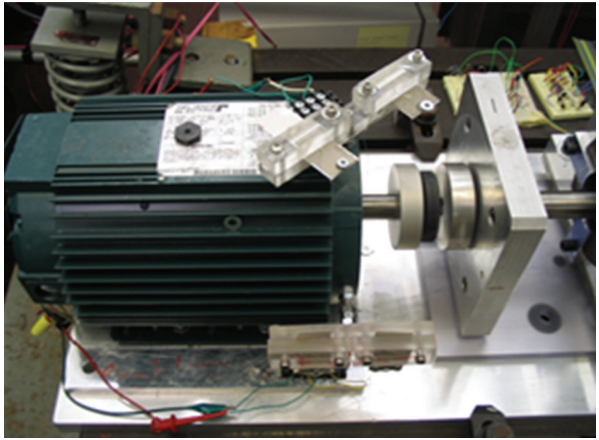

FIGURE 1: Photograph of motor test rig with the beam harvesters attached [2].

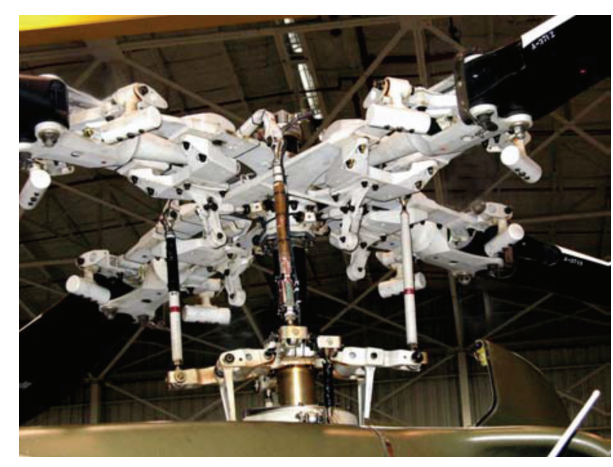

Figure 2: MicroStrain's Energy Harvesting, wireless loads tracking pitch link installed on Bell M412 [3].

components thereby improving safety, reducing the cost of flight testing, and enhancing condition based maintenance. Piezoelectric materials bonded to the pitch link, which is a control rod responsible for controlling the rotors' angle of attack and sustains high dynamic loads, harvested sufficient strain energy to successfully operate an integrated wireless sensor node during flight. Figure 2 shows the energy harvesting wireless sensor node installed on the pitch link of a Bell M412 helicopter.

Dumas et al. [16] also presented a smart wireless network of piezoelectric patches for damage detection in airplane and helicopter composite structures. Damage in the composite was evaluated by using the strain energy harvested from the vibrating structure to generate guided ultrasonic waves that are compared with stored reference signals. Finite element 


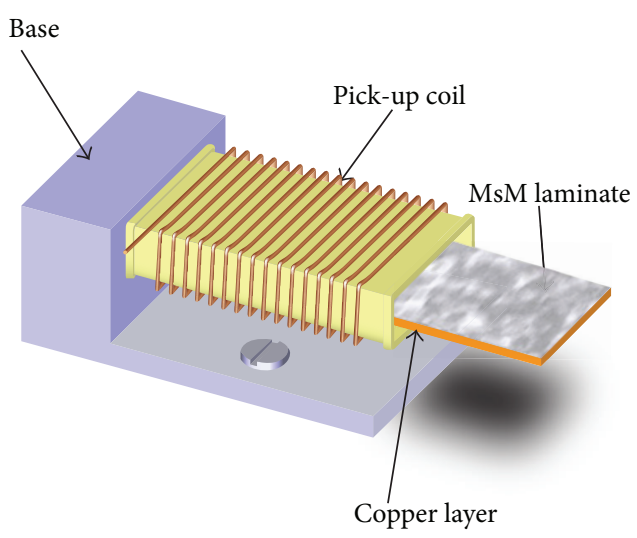

Figure 3: Prototype MsM energy harvesting Device [4].

simulations for wave propagation were completed and then compared with experimental results. A vibrational energy harvesting system for a wireless sensor device designed to improve the safety of operators using machinery to tow trailers was developed by Dondi et al. [17]. The harvester was a PZT cantilever tuned to resonate at the $112 \mathrm{~Hz}$ vibrations of the agricultural baler used in the case study. For vibration strengths ranging from 0.5 to $1.0 \mathrm{~g}$ 's, the energy harvester could generate $23 \mu \mathrm{W}$ to $850 \mu \mathrm{W}$ of usable power.

Recognizing some of the limitations of piezoelectric materials, like aging, depolarization, charge leakage, and brittleness, some researchers have developed vibration energy harvesters using magnetostrictive materials (MsM). MsM energy harvesters rely on the Villari effect whereby vibrationinduced strain of the material produces a change in its magnetization. As shown in Figure 3, Wang and Yuan [4] have developed a novel MsM energy harvester consisting of Metglas 2605SC bonded to a copper substrate wound by a pick-up coil. Under the dynamic loading of the vibration the change in magnetization of the MsM laminate is converted into electrical energy by the pickup coil according to Faraday's Law. An electromechanical model is derived using Hamilton's principle and Euler-Bernoulli beam theory, and a complete energy harvesting circuit consisting of a voltage quadrupler, ultracapacitor, and smart regulator is designed. Experimental results with a prototype showed that for a resonance frequency of $1.1 \mathrm{kHz}$ the average power density during charging of the ultracapacitor was $606 \mu \mathrm{W} / \mathrm{cm}^{3}$, which is comparable to the power density of piezoelectric energy harvesters. Ueno and Yamada [18] also propose an MsM energy harvesting device using iron-gallium alloy (Galfenol), which has a high robustness and low electrical impedance compared to piezoelectric materials, capable of producing $10 \mathrm{~mW} / \mathrm{cm}^{3}$. Their harvester is configured as a cantilever beam with two parallel beams of Galfenol connected to iron yokes by epoxy resin. Zucca and Bottauscio [19] present a comprehensive hysteretic model of an MsM harvester and study the time behavior of the magnetostrictive harvester with finite element modeling. The tested harvester consists of a $60 \mathrm{~mm}$ tall Terfenol-D rod with a $6 \mathrm{~mm}$ radius surrounded by a coil.
For input frequencies of $100-300 \mathrm{~Hz}$ the power generated across a resistive load varied up to $10 \mathrm{~mW}$. Another possible use of MsM materials in addition to energy harvesting is for vibrational damping. Davino et al. [20] consider a Terfenol-D rod as a vibrational damper/energy harvester and experimentally investigate the dependence of the mechanical damping on several parameters, including magnetic bias and resistive load. It was determined that an applied magnetic bias increases the harvested power and mechanical damping.

A detailed analysis combining some of the fundamental civil engineering problems with the problem of energy harvesting with piezoelectric materials has recently been completed by Erturk [21]. The first problem considered is the moving load problem, for which two methods of energy harvesting are presented-a piezoelectric cantilever and a piezoceramic patch. The second problem considered is the use of a piezoceramic patch to harvest energy from twodimensional surface strain fluctuations of large objects. Analytical derivations are presented for different input forces, and a case study of using a patch to harvest energy from surface strain on a steel multigirder bridge is discussed. Wischke et al. [22] demonstrated that piezoelectric energy harvesters could be used to harvest energy from the vibrations of railway ties in tunnels to power wireless sensor nodes. Because the analyzed traffic patterns revealed a broad spectrum of vibration frequencies and amplitudes, they designed an energy harvester with a broad frequency response by implementing an array of four PZT cantilevers with different resonance frequencies ranging from 437 to $498 \mathrm{~Hz}$. The cantilever harvesters were supported on both sides by solid state hinges to increase shock tolerance and limit the risk of device failure. Test results showed that the average energy harvested per passing train was $395 \mu \mathrm{J}$, which was enough energy to transmit an $\mathrm{RF}$ signal at each train passage. Future work would focus on the integration of an energy storage management system and microcontroller with the RF interface to develop a selfpowered wireless sensor node.

Like traffic tunnels, bridges are structures prone to damage from repeated dynamic loading. Most bridges in the USA are subject to infrequent visual inspections and are an aging and deteriorating infrastructure that make excellent candidates for SHM applications. Energy harvesting technologies are particularly well suited for bridge applications because it is very difficult to maintain batteries on sensors that must be located on, under, or within the structure. Therefore, many recent studies have examined the feasibility of using the low frequency vibrations of concrete and cable-stayed bridges to power SHM sensors. Jung et al. [23] conducted a field test on an in-service cable-stayed bridge using an electromagnetic energy harvester. The prototype device produced a maximum of $15.46 \mathrm{~mW}$ of power when attached to the bridge's stay cable. Kim et al. [24] later improved the performance of the prototype by replacing the electromagnetic induction components of the system with a movable mass and rotational generator. The system could be tuned to the frequency of the stay cable by changing the location of the proof mass. Results of a field test demonstrated that the normalized power of the improved device was $35.67 \mathrm{~mW}$, which was a significant improvement upon the output of the original prototype and 


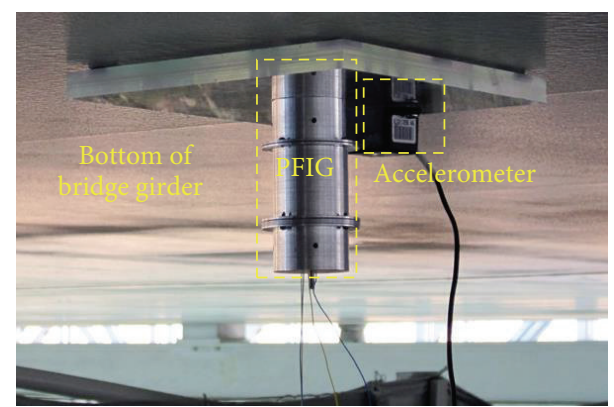

FIgURE 4: Photograph of the harvester attached underneath the bridge girder alongside a crossbow accelerometer [5].

is sufficient for sustaining a wireless sensor node for once-aday and twice-a-day measurements under gentle to moderate wind conditions. Another field test using an electromagnetic energy harvester was completed by Sazonov et al. [25]. A critical step in the design of the harvester was to set the natural frequency of the electromagnetic generator equal to one of the natural frequencies of the bridge. A maximum of $12.5 \mathrm{~mW}$ of power was harvested from bridge vibrations induced by passing traffic.

To improve the energy harvesting performance from bridges that have low acceleration, low frequency, and nonperiodic vibration, a parametric frequency-increased generator (PFIG) was developed by Galchev et al. [5] as shown in Figure 4. In the PFIG a centrally located mass that moves in response to the vibrations is used to induce high frequency mechanical oscillations in an electromechanical transducer. Advantages of the system are that it efficiently converts the low-frequency bridge vibrations and can be used in an unpredictable environment due to its nonresonant operation. After developing an analytical model, Galchev et al. fabricated and tested the energy harvester on a linear shaker where its operation over a large acceleration and frequency range (up to $30 \mathrm{~Hz}$ ) was demonstrated. The harvester was also tested on the main span of the NC Bridge in Vallejo, California. The harvester produced $0.5-0.75 \mu \mathrm{W}$ of average power without any tuning or modification.

In [26] Wardlaw et al. propose a self-powered wireless sensor system for the structural health monitoring of highway bridges. Their energy harvester uses magnetic shape memory alloy (MSMA), which can covert mechanical work into a magnetic induction change, to first convert the bridge vibrations into a magnetization change and then, with the assistance of a pickup coil, into an alternating current. Circuits were also proposed for important elements of the system and some of the most key components, including rectification circuitry, were designed and fabricated. Peigney and Siegert [27] use the short time pulses of highway bridge vibrations to develop a model that predicts harvested power based on traffic statistics. A piezoelectric cantilever bimorph consisting of a tip mass and two Milde QP20W piezoelectric patches bonded to the clamped end of a steel plate was fabricated and tested. The device produced up to $30 \mu \mathrm{W}$ of power during peak traffic intensity and could potentially be used to power wireless sensor nodes with low duty cycles. Xiang et al. [28] consider harvesting energy from the deformation of pavement under moving vehicles for the powering of wireless health monitoring sensor nodes mounted on civil infrastructure. They propose embedding a piezoelectric transducer operating in the $d_{31}$ mode under the pavement to convert bending energy to electrical energy. The pavement is described as an infinite Euler-Bernoulli beam resting on a Winkler foundation and an analytical model is developed with the Fast Fourier transform method and Cauchy's residue theorem. Numerical simulations are presented that examine the effect of vehicle velocity, level of damping, and foundation condition. Depending on system parameters, the harvested power for a vehicle moving with a velocity of $30 \mathrm{~m} / \mathrm{s}$ was approximately $0.5 \mathrm{~W}$.

In addition to considering the vibrations of civil structures like tunnels, bridges and roads, researchers are continuing to investigate the harvesting of energy from vibrating fluid systems. Cunefare et al. [29] explore harvesting energy from pressure fluctuations in hydraulic systems to power SHM sensors. Hydraulic pressure energy harvesters (HPEH) that convert pressure ripple, which is the peak-to-peak amplitude of the dynamic pressure, present in hydraulic systems into electricity by utilizing a piezoelectric stack arrangement are introduced. The high energy density of the hydraulic system associated with its pressure and flow enabled generation of usable power even when the system operated off-resonance of the piezoelectric stack. The initial HPEH prototype was tested on a hydraulic pump system that included a nonpiston pump operating at $1500 \mathrm{rpm}$ and provided power outputs of up to $1.2 \mathrm{~mW}$ from a dynamic pressure ripple of $400 \mathrm{kPa}$. $\mathrm{Li}$ and Tse [30] present a design for an energy-harvesting hydraulic damper that simultaneously damps vibrations and harvests energy. Vibration acting on a hydraulic damper is converted into amplified rotation of a hydraulic motor, and an electromagnetic generator connected to the output of the motor provides harvested power. An analytical model for predicting mechanical and electrical responses was developed and a prototype device was fabricated and tested. The maximum harvested power was $435.1 \mathrm{~W}$ for a $0.8 \mathrm{~Hz}$ frequency. System performance deteriorated for highfrequency, high-amplitude vibrations. Li et al. [6] consider a similar problem and propose an innovative regenerative shock absorber design that uses an electromagnetic energy harvester based on a mechanical motion rectifier (MMR) that converts oscillatory vibration into unidirectional rotation of the electrical generator. A dynamic model of the mechanicalelectrical system is developed with a circuit-based method and both simulations and laboratory experiments are conducted. During a road test a prototype of the device that was mounted on the suspension of a Chevrolet Suburban traveling at $15 \mathrm{mph}$ on a smooth paved road produced $15.4 \mathrm{~W}$ of power. A 3D model and picture of the prototype energy harvesting shock absorber with MMR are shown in Figure 5.

Over the past decade, technology used to harvest mechanical vibrations has started to transition beyond the realm of the research laboratory to commercial application. For instance, established in 2004, Perpetuum is a leading company in energy harvesting technology and provides an electromagnetic energy harvester for use with wireless sensor 


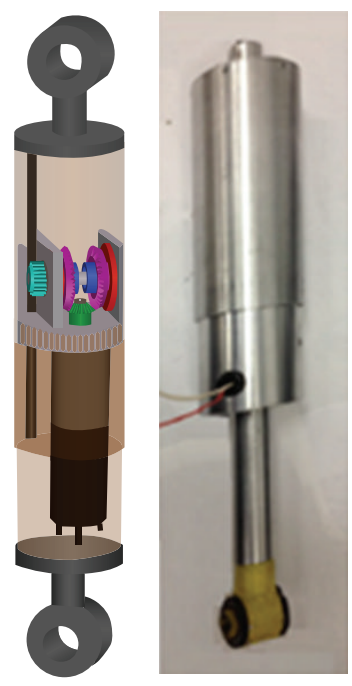

FIGURE 5: 3D model and actual prototype of the shock absorber with mechanical motion rectifier [6].

systems in industrial and rail applications. The harvester converts vibration to electrical energy via an oscillating magnet that transverses across a fixed coil. It was recently announced that Perpetuum would supply wireless sensor systems for all 148 of the Electrostar train stock owned by Southeastern Railways [31]. The self-powered sensors will collect vibration data from moving trains that will be transmitted wirelessly to a database where software will look for bearing and wheel wear. This will enable maintenance engineers to create condition-based maintenance programs that will improve reliability and safety and also reduce costs.

2.2. Wind and Aeroelastic Vibrations. The use of wind as an alternative energy source for large-scale power production is a well-developed technology that continues to receive much attention due to climate change. However, harvesting energy from wind to sustain low-power electronics for use in SHM applications is a relatively recent development. Given that many bridges are located in windy areas, the harvesting of kinetic energy from wind has received much attention as a potential power source for wireless sensors designed to monitor the health of these structures. Park et al. [32] investigated the feasibility of using small scale wind generators, referred to as microwind turbines, to power wireless sensors on a cable-stayed bridge. Wind tunnel tests were conducted with three different rotors in order to determine the turbine that delivered the peak power performance. For a $7 \mathrm{~m} / \mathrm{s}$ wind speed the $13.8 \mathrm{~cm}$ diameter, six-blade turbine generated a maximum output of $438.79 \mathrm{~mW}$ and maximum power density of $2.93 \mathrm{~mW} / \mathrm{cm}^{2}$. Another experiment with the 6-blade turbine, wireless sensor node, and charging circuit intended to verify the system's actual power-charging capability demonstrated that the microwind turbine could generate sufficient electricity for wind speeds greater than $4 \mathrm{mph}$. Xu et al. [33] develop an equivalent circuit model of the microwind turbine to predict the output power and net efficiency of the system. Experiments were then conducted with a system comprised of commercially available off-theshelf components and a $6.2 \mathrm{~cm}$ plastic blade. The maximum output power of the turbine reached $18 \mathrm{~mW}$ at a wind speed of $4.5 \mathrm{~m} / \mathrm{s}$.

As reviewed in Section 2.1, to date most work on the harvesting of energy from mechanical vibrations has focused on the use of ambient vibrations present in the system or environment. More recently, some researchers [7, 34] have begun to consider the harvesting of energy from vibrations due to induced aerodynamic instability phenomena such as galloping, flutter, and vortex induced vibration. These energy harvesters may provide advantages compared to microwind turbines that pull kinetic energy from the wind because conventional, geared rotating airfoils can be too expensive or inefficient for some locations. Also, miniaturization of wind turbines reduces their overall efficiency because of mechanical losses at the bearings. Jung et al. [34] completed wind tunnel tests of an electromagnetic energy harvester designed to harvest energy from vibrations due to wake galloping, which is an aerodynamic instability phenomenon caused by the wake interference between two cylinders. When the cylinders begin to vibrate, which during tests began at a wind speed of $0.5 \mathrm{~m} / \mathrm{s}$, permanent magnets are moved through solenoid coils. Wind tunnel tests were completed for cylinders $85 \mathrm{~cm}$ long with a $5 \mathrm{~cm}$ diameter, and the average power generated was $0.3-1.13 \mathrm{~W}$ for wind speeds ranging from 1.8 to $5.6 \mathrm{~m} / \mathrm{s}$. Sirohi and Mahadik [7] present an analytical model for a piezoelectric wind energy harvester design that harvests energy from a prismatic body oscillating due to aerodynamic galloping (Figure 6). Transverse galloping of an elastic bluff body occurs when the wind speed across the body exceeds a certain critical value that depends on multiple parameters. The analytical model consists of two parts, a structural model developed with the energy method and an aerodynamic model. During wind tunnel tests, the prototype device generated a maximum output power of more than $50 \mathrm{~mW}$ at a wind speed of $11.6 \mathrm{mph}$ (Figure 7), which is sufficient power to supply most of the commercially available wireless sensors currently in use.

Abdelkefi et al. [35] extend the analysis of energy harvesting from transverse galloping of a bluff body by studying the performance of a piezoelectric transducer attached to the transverse degree of freedom of three different cross sections: a square, isosceles triangle, and D shape. The effects of load resistance and cross section geometry on transverse displacement, voltage output, and harvested power were considered. Modeling results demonstrated that for low and high wind speeds the isosceles triangle and D cross sections, respectively, were the best for harvesting power. For additional research by Abdelkefi et al. on piezoaeroelastic energy harvesters the reader is referred to [36-39]. Wu et al. [8] use a cantilever beam to harvest energy from vibrations induced by vortex shedding, which is an oscillating flow where vortices are created periodically and then detach from the leeward side of slender beams. As fluid flows across it, the beam tends to move toward the low pressure zones created by the low pressure vortices and, as a result, the pressure variations from the vortex shedding create a crosswind induced vibration. The beam Wu et al. designed consists 


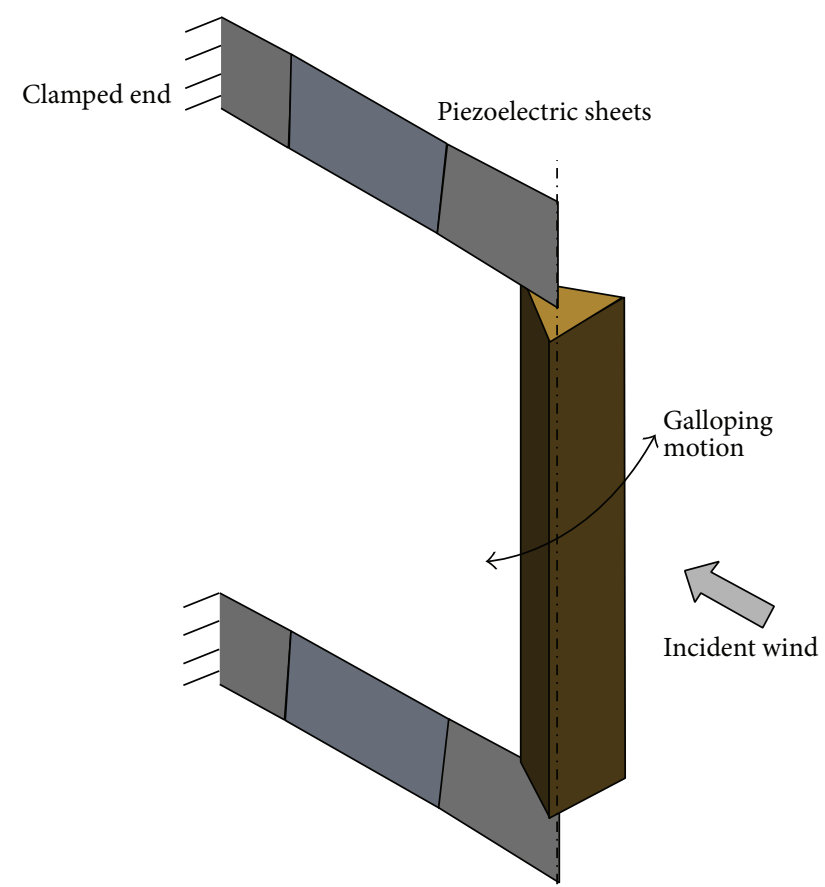

FIGURE 6: Galloping energy harvester with tip body having equilateral triangle cross section [7].

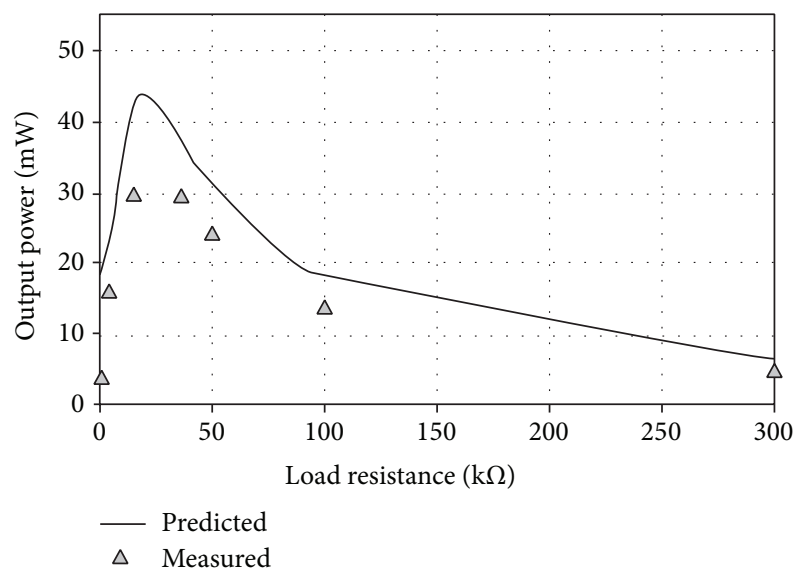

FIGURE 7: Correlation between measured and predicted output power for an incident wind speed of $10 \mathrm{mph}$ [7].

of two piezoelectric PZT4 patches bonded to Polysulfone (PES) and is shown in Figure 8. A comprehensive numerical model is developed to calculate the response of the harvester and the total electric power generated, and simulations focus on the effects of piezoelectric patch locations and dimensions. The RMS for the generated power of a harvester with the dimensions $1.2 \times 0.15 \times 0.012 \mathrm{~m}$ having a $12 \mathrm{~kg}$ proof mass and exposed to a variable wind velocity of $9-10 \mathrm{~m} / \mathrm{s}$ was $1.02 \mathrm{~W}$.

Kwon [40] proposed a T-shaped piezoelectric energy harvester designed to harvest energy from aeroelastic flutter, which for the tested device occurred at a wind velocity of $4 \mathrm{~m} / \mathrm{s}$. Six PZT-5A PZT ceramics were bonded to both sides of the harvester's fixed base in a bimorph cantilever

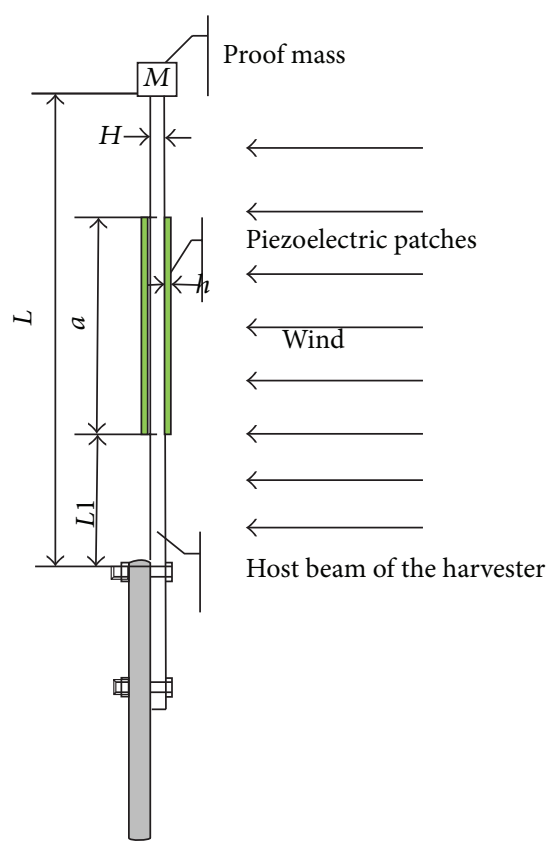

FIGURE 8: Piezoelectric harvester subjected to wind load [8].

configuration. At the onset of aeroelastic flutter the maximum power produced by the device was $0.35 \mathrm{~mW}$ and for a wind velocity of $15 \mathrm{~m} / \mathrm{s}$, which was the maximum tested wind velocity, the power produced was $4 \mathrm{~mW}$.

2.3. Kinetic Energy of Rotation. Systems designed to harvest kinetic energy from flowing fluids, like the winds present around bridges, were reviewed in Section 2.2. Researchers have also recently developed energy harvesters for wireless SHM sensors that are designed to directly convert the kinetic energy of rotating system components into usable electrical power. For example, Wang et al. [41] present a design for a rotating energy harvester that is based on magnetostatic coupling between a stationary circular-arc hard magnet array and rotating magnetic solenoids. When installed on a wheel rotating at $60 \mathrm{mph}$, the prototype device produced a maximum output voltage of $9.2 \mathrm{~V}$ and power density of $4.5 \mathrm{~W} / \mathrm{cm}^{3}$ and was demonstrated to be a viable method for powering a real-time tire pressure monitoring system (TPMS).

For all rotating machines and structures, like turbines, for example, real-time condition monitoring is highly desirable in order to achieve improved safety and equipment performance. Khameneifar et al. [9] investigated a vibration-based energy harvester for rotary motion health applications (e.g., strain gauges and accelerometers). The novel design consisted of a piezoelectric cantilever with tip mass mounted on a rotating hub (Figure 9). During rotation of the cantilever beam the alternating gravitational force on the tip mass generates continuous oscillations. An analytical model developed with the energy method is presented for predicting the maximum output power and optimal resistive load. Experimental tests were then conducted with two different energy harvesters, 


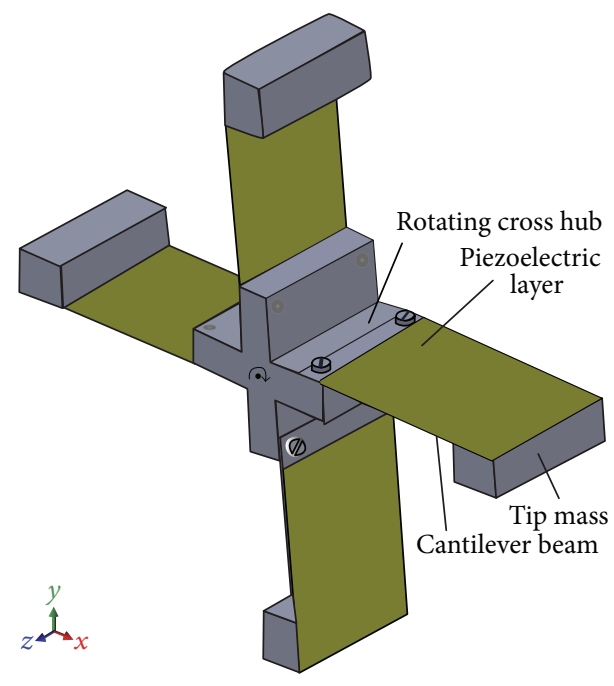

FIGURE 9: Schematic view of the energy harvester mounted on a rotating hub [9].

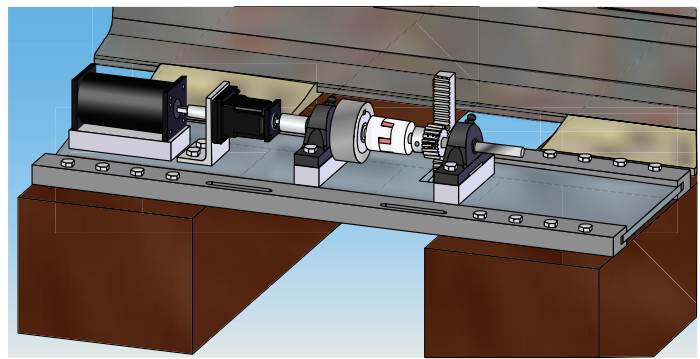

Figure 10: Device shown mounted across two ties of a section of railroad track [10].

one using PZT and another utilizing PVDF film. For proof of concept demonstration only one cantilever beam was installed on the hub during the experiment. After tuning the hub's angular velocity to match the harvester's natural frequency, the load resistance was varied until maximum power was achieved. The amplitude of the generated power from the PZT transducer was approximately 44 times higher than that of the PVDF transducer. The $6.4 \mathrm{~mW}$ of power obtained from the PZT harvester beam with a tip mass of $105 \mathrm{~g}$ is enough for supplying a typical wireless sensor. Power levels generated by the PVDF harvester were only suitable for sustaining wireless sensors in the sleeping state. The authors noted that a limitation of the PZT transducer was that the brittle material could fail if the hub was exposed to large variations in torque and that the more flexible PVDF film might be preferred.

Nelson et al. [10] and Phillips et al. [42] examine harvesting energy from passing railroad cars to power warning lights and track health monitoring systems. The prototype energy harvester converts the vertical displacement of the railroad track and ties due to the passing cars into rotational motion with a rack and pinion gear. The rotational motion is then converted by a small generator into electrical

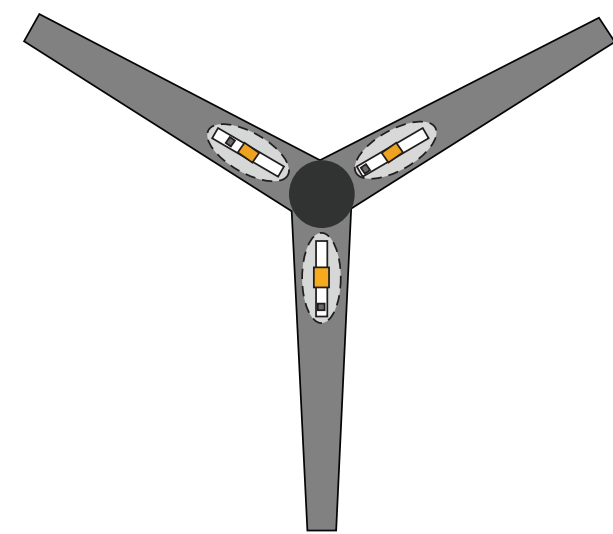

FIGURE 11: Energy harvesters placed inside the blades of a wind turbine [11].

energy (Figure 10). A computer simulation was developed for determining the maximum power potential for different prototypes with various railcar loads and speeds. Field tests validated the simulation results for the power production of a single device $(0.317 \mathrm{~W})$ for a loaded train traveling at $11.5 \mathrm{mph}$.

Joyce [11] developed an electromagnetic energy harvester consisting of a magnet inside a tube surrounded by coils designed to monitor the structural health of large wind turbines. When mounted on the rotating turbine blades the changing orientation of the blade causes the magnet to slide along the tube thereby generating the voltage required to power the SHM system. A schematic of the harvesters mounted on the turbine blades is shown in Figure 11. Experimental results showed that a sample harvester could produce up to $14.1 \mathrm{~mW}$ when attached to a blade spinning at 19 RPM.

2.4. Thermal Energy. Another method of obtaining energy from ambient sources is by taking advantage of thermal gradients with thermoelectric generators (TEGs) operating on the Seebeck effect, which describes the generation of an electric current at the junction of dissimilar metals at different temperatures. In order to construct a TEG numerous $p$-type and $n$-type junctions are arranged electrically in series and thermally in parallel [1]. The TEG is a mature technology that has been extensively studied over the past three decades. An advantage of a TEG compared to a vibration-based energy harvester is that it has no moving parts. Disadvantages are that TEGs are relatively inefficient when low thermal gradients are present and that until recently the dimensions and weight of the devices were too large to integrate them with MEMS technologies [1].

Because aircrafts flying at high altitudes are subject to large thermal gradients, the use of TEGs to power wireless SHM sensors for aerospace applications is a field of interest. Pearson et al. [12] investigated using piezoelectric materials and TEGs to harvest ambient vibration and thermal gradients, respectively, present on aircraft. Simulation results utilizing temperature data taken from thermocouples placed at various positions on an aircraft (Figure 12) yield peak 
TABLE 2: Simulated power levels for temperature gradients on an aircraft [12].

\begin{tabular}{lccc}
\hline & Peak temperature differential, ${ }^{\circ} \mathrm{C}$ & Peak power, mW & Average power, $\mathrm{mW}$ \\
\hline $\begin{array}{l}\text { Cargo skin } \\
\text { Cargo primary Insulation }\end{array}$ & 40 & 34.15 & 22.58 \\
\hline $\begin{array}{l}\text { Hydraulic pipeline 1 } \\
\text { Hydraulic pipeline 2 }\end{array}$ & 20 & 5.97 & 3.07 \\
\hline $\begin{array}{l}\text { Waste water tank } \\
\text { Waste water ambient }\end{array}$ & 15 & 18.72 & 2.99 \\
\hline $\begin{array}{l}\text { E-bay fuselage skin } \\
\text { E-bay primary insulation }\end{array}$ & 35 & 13.36 & 3.42 \\
\hline $\begin{array}{l}\text { Cabin wall fuselage skin } \\
\text { Cabin wall primary insulation }\end{array}$ & 30 & 30.06 & 3.97 \\
\hline $\begin{array}{l}\text { Cabin wall fuselage skin } \\
\text { Cabin wall secondary insulation }\end{array}$ & 40 & 11.70 \\
\hline
\end{tabular}

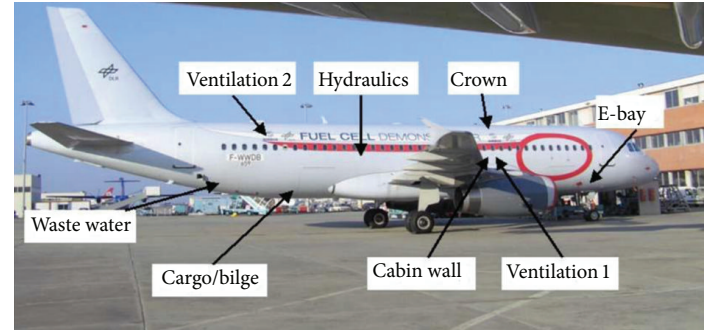

FIGURE 12: Locations of thermocouples used for the TEG power output simulation [12].

power levels ranging from 5.46 to $34.15 \mathrm{~mW}$ depending on the location of the thermocouple as shown in Table 2 [12].

Becker et al. [43] also propose an autonomous sensor system for monitoring strain in advanced aircraft materials. Solar cells, vibrations generators, and thermoelectric generators are considered for the energy harvesting method. In a laboratory test, a TEG was connected to a sensor platform and power management and storage system. For a thermal gradient of $70^{\circ} \mathrm{C}$ the power generated by the TEG was approximately $20 \mathrm{~mW}$, which was stated to be enough to sustain autonomous operation of the sensor node and its related data communication protocols. Samson et al. $[44,45]$ improve upon the performance of their aircraft specific thermoelectric generator module by adopting a new TEG prototype for their module and modifying the power management system. The prototype TEG used, which was a TG1-2000 from Marlow Industries, Inc., was based on a specially doped semiconductor alloy and was designed for the temperature range experienced by an aircraft during takeoff and landing from a short-range flight. Use of the prototype TEG increased the heat to electricity conversion by approximately $14 \%$, and modifications to the capacitors in the power management system added another $36 \%$ improvement in power management. The authors completed numerical simulations and laboratory experiments in preparation for validation on a future test flight.
Using proprietary technology Micropelt has developed a MPG_D655 thermogenerator chip that has more than 100 pairs of $p$-type and $n$-type thermoelectric legs per square millimeter [46]. This enables the chip to provide a high power density from temperature gradients with a stated open circuit voltage output of $80 \mathrm{mV} / \mathrm{K}$. The typical dimensions of the compact chip are $3340 \times 2465 \times 1090 \mu \mathrm{m}$. The prototype device, which is still being optimized and is only available for testing and evaluation, is proposed as potential power supply for wireless sensor network applications where waste heat is available.

2.5. Solar Energy. Wireless SHM sensor networks that harvest solar energy use photovoltaic (PV) cells, or solar cells, that convert the sun's energy into usable electricity. In brief, when sunlight strikes a PV cell photons are absorbed by semiconducting materials like silicon. The energy from the photons loosens free electrons that then flow as current due to the presence of an electric field that has been created by the separation of charge carriers in the cell. Placing contacts on the top and bottom of the cell allows DC current to be extracted. As shown in Table 1, solar energy harvesters exposed to direct sunlight provide the highest relative power density of the energy harvesting methods considered. However, a limitation of solar energy harvesting is that the sun will not shine 24 hours a day. Also, PV cells are current sources and do not supply a constant voltage. So, despite the high power density provided, systems using PV cells need an integrated energy storage device such as a rechargeable battery.

Because of their high power density, solar energy harvesting methods have received much consideration for outdoor SHM applications, like roads and bridges. As solar panels/energy harvesters are a relatively well-developed technology, the research reviewed in this paper focuses on implementation and validation of the complete network rather than further recent enhancements of the harvesting method or developments in photovoltaic technology. Hassan et al. [47] have developed and tested a novel solar energy harvesting evaluation kit for monitoring the propagation of cracks in 


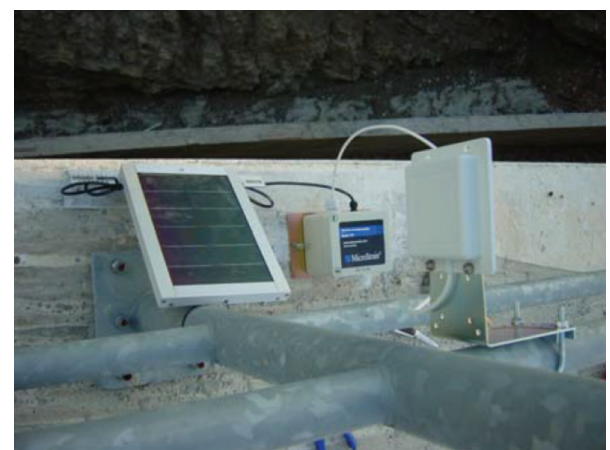

FIGURE 13: Solar powered wireless G-link seismic sensors on Corinth Bridge, Greece [3].

concrete structures. The complete system included a solar panel connected to two batteries and a power management block. Inamdar [48] also proposed several designs of a solar energy harvester system developed to monitor the strains of bridges. A PV array performance model was used to determine the proper PV size, battery bank size, and panel orientation. A prototype solar energy harvester optimized according to results from physical experiments and the analytical model was then designed and fabricated.

Some complete solar-powered SHM systems are already commercially available. For example, Arms et al. [3] have reviewed the installation of a commercially available solar powered wireless G-Link seismic sensor developed by Microstrain, Inc. The particular unit discussed is shown in Figure 13 and was installed on the Corinth Bridge in Greece. This particular system uses an array of wireless accelerometer nodes attached to solar panels to continuously monitor the bridge span's vibration levels. Should any node detect seismic activity, the entire network is alerted and data is collected simultaneously from all of the nodes.

Miller and Spencer Jr. [49] propose a smart sensor network for civil structures developed by the Newmark Structural Engineering Laboratory (NSEL) at the University of Illinois at Urbana-Champaign. The complete system uses the Imote2 smart sensor, custom-designed multimetric sensor boards, base stations, and software provided by the Illinois Structural Health Monitoring Project (ISHMP) Services Toolsuite. The smart sensor network was experimentally validated during a test on the Jindo Bridge in South Korea. The test involved 70 total sensor nodes, eight of which were equipped with solar energy harvesters. Five of the solar harvesting nodes were installed on cables, two were installed on top of pylons, and one was placed on the bridge deck. The objective of the test was to track the voltage of the rechargeable batteries connected to the solar energy harvester and the current and voltage from the solar panels. Evaluation of the test data is provided by Jang et al. [50]. Over the course of 40 days, seven of the eight solar energy sensor nodes maintained battery voltage levels above 4.1 volts, which was an indication that these energy harvesters provided sufficient long-term power for sensor operation. The harvester that did not provide sufficient power was mounted at the deck level under the box girder and relied on reflected sunlight for most of its energy. Therefore, other energy harvesting methods already reviewed, like scavenging ambient bridge vibrations, may be more viable for sustaining sensor nodes in areas of low direct sunlight.

2.6. Combination of Energy Harvesting Methods. In many environments where multiple sources of ambient energy are present it may be possible to develop an energy harvesting strategy that utilizes multiple transduction mechanisms. For example, a wireless SHM network on a vibrating highway bridge in a windy location could rely on a combination of piezoelectric cantilevers, microwind turbines, and solar panel. Such an approach could provide redundancy in the event that the operating conditions deteriorate for a certain transduction method. For example, the resonant cantilevers could possibly sustain the system and compensate for the turbines on cloudy days when winds are nonexistent. For this reason, researchers have completed or are completing projects where the combination of multiple methods of energy harvesting is explored. A four-year cross-disciplinary project supported by Mistras Group Inc., Virginia Tech, the University of South Carolina, and the University of Miami to develop a self-powered wireless sensor node for steel and concrete bridges has been reviewed by Godínez-Azcuaga et al. [51]. For the energy harvesting component of the project the research team is considering the integration of miniature wind turbines and nonlinear vertical piezoelectric windmills. The miniature wind turbines produced electrical power in the range of 100 to $700 \mathrm{~mW}$ when the wind speed was between 6 and $11 \mathrm{mph}$, and the nonlinear piezoelectric windmill was a possible alternative for lower wind speeds. A mat type harvester containing piezoelectric patches and designed to be embedded in the pavement in order to harvest energy from strain fluctuations induced by pressure loading from passing traffic was also under consideration.

Farinholt et al. [52] have reported on the use of a wireless sensor system that relies on a hybrid approach combining several transducer types to harvest energy from multiple sources. Piezoelectric bimorph cantilevers and TEGs were considered for harvesting ambient vibrations and thermal gradients, respectively, from the Omega Bridge in Los Alamos, New Mexico. Vibration data was collected in order to identify the fundamental frequencies of the bridge, and a PZT bimorph cantilever was fabricated and tuned so that its fundamental frequency matched one of the fundamental frequencies observed in the vibration response of the bridge. Temperature differences between the concrete deck of the bridge and the ambient air were also recorded. During a laboratory experiment using an electromagnetic shaker and hot plate, the PZT harvester and TEG were coupled in order to determine the time required to charge a capacitor to the $3.5 \mathrm{~V}$ required to operate the selected sensor node. After $912 \mathrm{~s}$ of charging the node powered on and performed 100-point measurements on three sensors used to monitor bolt preload. This charging rate would provide an operating cycle sufficient for applications where data would only need to be recorded several times a day. The use of wireless energy transmission from an RF energy source to supplement energy harvesting approaches was also considered. 


\section{Nonlinear Energy Harvesting}

It is well documented that a limitation of vibration-based energy harvesters is their narrow operating bandwidth [53]. Optimal performance is obtained when the harvester operates at its fundamental resonance frequency, which typically peaks over a very narrow range. However, frequency matching between the harvester and ambient vibrations can be difficult because of manufacturing tolerances, electric load changes, and excitation frequency changes as most sources do not have constant frequency spectrums [54]. For this reason, the energy harvesting community has transitioned its focus to the concepts of broadband energy harvesters, which will be discussed first, and tunable harvesters, both of which can provide optimal performance over a larger range of input frequencies as compared to linear, resonant harvesters. Note that there have been numerous studies published in the area of nonlinear energy harvesting over the past five years, so the literature reviewed here is only meant to provide an introduction to ongoing developments in the field. For a recent comparison of linear and nonlinear energy harvesters refer to the recent work by Beeby et al. [55]. Their research presents analytical models of linear, bistable, and nonlinear energy harvesters for the electromagnetic and piezoelectric transduction mechanisms. Computer simulations of power output are completed for the three types of energy harvesters using vibration data taken from measurements of a diesel ferry engine, heat and power pump, car engine, and white noise vibration. Results show the importance of simulations and the use of real vibration data for selecting and optimizing energy harvesters for a particular application.

A broadband energy harvester using a piezomagnetoelastic generator has recently been proposed by Erturk et al. [56]. The device consists of a ferromagnetic cantilevered beam with two permanent magnets located symmetrically near the free end. Depending on the spacing of the magnets the magnetoelastic structure can have multiple equilibrium positions. Two layers of PZT-5A are attached to both faces at the beam's root in order to create an energy harvester. Laboratory experiments are conducted to determine the response of the nonlinear, piezomagnetoelastic structure to harmonic base excitation. The magnets are then removed so as to compare the performance of the nonlinear harvester with a standard resonant harvester. Whereas the resonant harvester without magnetic buckling only provided a larger voltage output near its resonance frequency $(7.4 \mathrm{~Hz})$, and the output of the nonlinear harvester was up to three times that of the resonant harvester at frequencies below its resonance frequency $(10.6 \mathrm{~Hz})$. It was noted that the piezomagnetoelastic harvester provided a $200 \%$ increase in the open-circuit voltage amplitude.

The use of magnets in the development of nonlinear harvesters is a common theme. Lin et al. [57] have demonstrated how the power output of piezoelectric cantilever beam can be enhanced by applying a simple repulsive force. Experimental results showed that the magnetically coupled cantilever responded to vibration over a much broader frequency range than the standard beam and provided no reduction in performance at the resonant frequency during application of a symmetric magnetic force. A harvester configuration utilizing a cantilevered beam with a permanent tip magnet has been modeled and studied by Wickenheiser and Garcia [58]. Ferromagnetic structures, which remain stationary while the base moves, are placed near the tip of the vibrating beam to create a sequence of wells of attraction. This rectification approach induces vibrations at the resonant frequency of the beam regardless of the input frequency thereby increasing the broadband behavior of the beam compared to the standard cantilever harvester. During simulations the proposed magnetic rectification approach is shown to harvest $400 \%$ of the power of the linear design. The theoretical analysis and analytical solutions for a nonlinear vibration energy harvester based on statically stable diamagnetic levitation have been completed by Liu and Yuan [59]. The proposed design uses spiral coils made of diamagnetic materials to provide nonlinear restoring forces. Potential advantage of the untested device is that it has no mechanical energy loss due to material friction and/or damping and that it can provide a wide bandwidth response. Barton et al. [60] have presented a broadband electromagnetic energy harvester where the nonlinearity is created by the arrangement of magnets in conjunction with an iron-cored stator. An important experimental finding was that the advantages of the wide bandwidth provided by their design were only present when there was an uninterrupted/nonrandom vibration source. This observation prompted Barton et al. to further investigate incorporating a restarting mechanism to overcome the sudden drops associated with random source vibrations thereby maintaining the harvester in an optimal energy state.

Whereas broadband energy harvesting is a field receiving much attention, other researchers [54, 61] have focused on tuning the frequency of resonant harvesters to accommodate changes to the excitation frequency. Two of the tuning methods investigated are the application of axial loads and the use of magnets, both of which change the harvester's transverse stiffness. Al-Ashtari et al. [54] used magnets to design and test an energy harvester with a tunable resonance frequency. Cottone et al. [61] modeled and tested a buckled beam under axial compression that exhibited superior power generation compared to the unbuckled beam. Rhimi and Lajnef [13] use the Hamiltonian Principle to analytically estimate the power output of a bimorph piezoelectric cantilever beam that is preloaded with a variable axial stress applied by adjusting two metallic springs connecting the tip of the beam to the base as shown in Figure 14. The derived model encompasses all of the theoretical vibration modes of the beam. Experimental results of the response of the bimorph energy harvester to varying preload conditions validated the theoretical model (Figure 15). Using recorded vibration data of a bridge under ambient loading, it was demonstrated that an application of $8 \mathrm{~N}$ of compressive axial force increased the energy harvester's power output 2.5 times compared to the unloaded condition [13].

The modeling and testing of an energy harvester designed to convert ambient vibrations generated by a nuclear facility's ventilation fans into the electrical power required to sustain a wireless industrial health system providing feedback about the ventilation system's performance were also presented by 


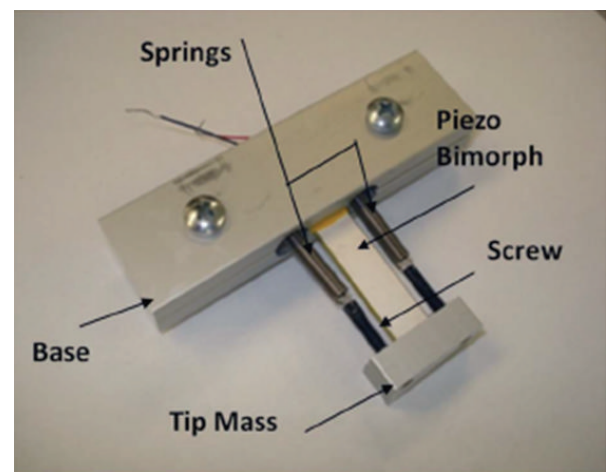

FIGURE 14: Experimental setup: loaded piezoelectric bimorph beam with attached tip mass [13].

the authors [14]. Because the vibration frequencies of the fans change due to varying plant ventilation requirements, harvesters that can provide useful power across a range of frequencies are required. Therefore, energy harvesters that can be tuned by using magnets to adjust the harvester's stiffness were considered. Figure 16 shows a picture of the experimental setup with the adjustable slide and magnets. Figure 17 compares the tuned and untuned power outputs of the energy harvester with respect to frequency. For all measurements the load resistance remained constant at 180 $\mathrm{kohm}$. The untuned data points represent the power output of the harvester as the input frequency of the excitation force is adjusted away from the harvester's fundamental frequency of $39 \mathrm{~Hz}$ and the tuned data points represent power output after the magnets have been used to tune the harvester to the new input frequency. The data show that, as expected, variations in the excitation frequency cause marked deterioration in system performance of the linear harvester and that the power output of the tuned beam was significantly better than the output of the untuned beam. The deteriorating performance of the tuned beam for increasing input frequencies is assumed to be due to the loss of the impedance match between the source and load as the harvester's stiffness and resonance frequency are adjusted with the magnets.

Some researchers [58] have noted that frequency tuning can be considered "quasistatic" because the rate at which the fundamental frequency is tuned is usually much slower than the excitation frequency. Likewise, compared to the response of nonlinear, broadband harvesters the response of tunable harvesters is still linear and, rather than increasing the harvester's band of efficient operation, tuning shifts the center point. In addition to a potential lag between excitation frequency changes and harvester tuning, another potential drawback of tunable harvesters is that active tuning may require using some of the harvested power thus reducing the amount available for the load. For this reason passive tuning is typically preferred.

\section{Conclusion}

This paper reviews some of the advances from 2008 to 2013 in the field of energy harvesting technologies for the SHM

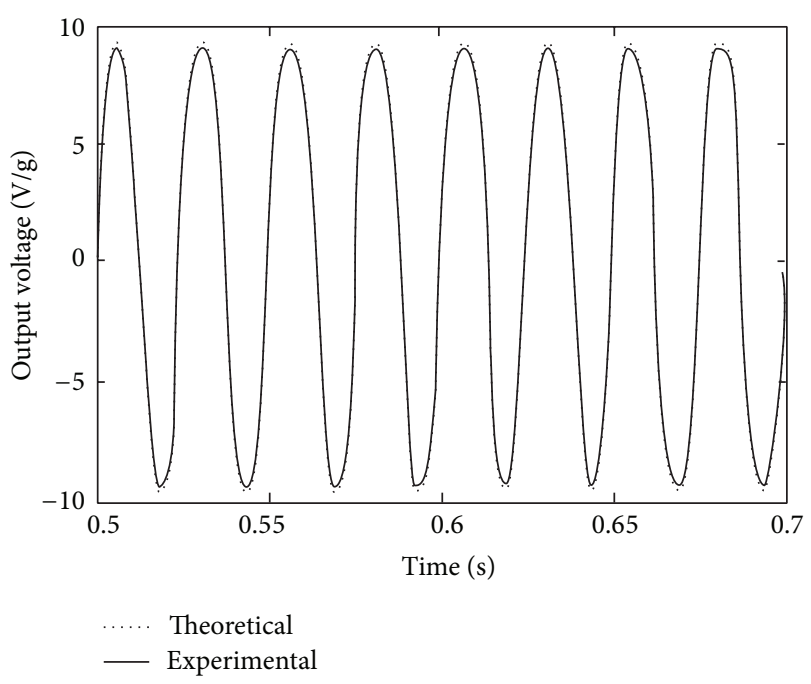

FIgURE 15: Predicted and measured output voltage across a $10 \mathrm{M} \Omega$ resistance: frequency $=40 \mathrm{~Hz}$, axial preload $=-2 \mathrm{~N}$, and tip mass $=3.75 \mathrm{~g}[13]$.

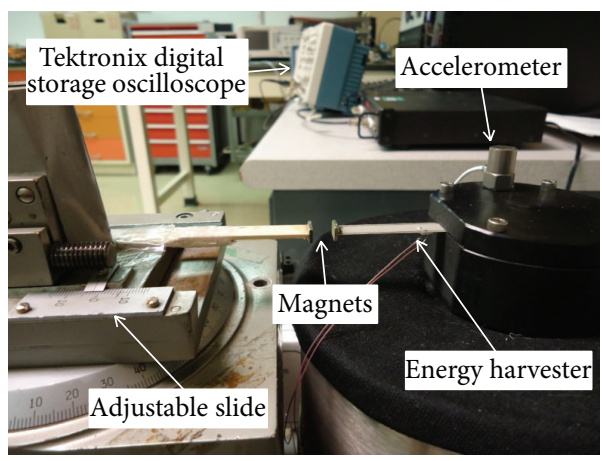

FIGURE 16: Photograph of the experimental setup for tuning the harvester with magnets [14].

of machinery, civil, and aerospace applications. The method of energy harvesting is one of the major considerations in the design of any self-powered, wireless SHM system. The most common ambient energy sources, which include mechanical vibrations, wind, rotational kinetic energy, and solar and thermal energy, used for SHM systems are briefly overviewed. An introductory survey of nonlinear energy harvesters and some of the frequency tuning methods developed for linear, resonant piezoelectric harvesters is also presented. Current trends are towards further development of nonlinear, vibration-based energy harvesters and the integration of multiple harvesting methods for the sustained, efficient operation of wireless sensor networks. The development of autonomous, self-powered SHM systems powered by the harvesting of ambient energy from the local environment is an area of research that offers much potential and will continue to expand in combination with new developments in the field of low-power electronics. 


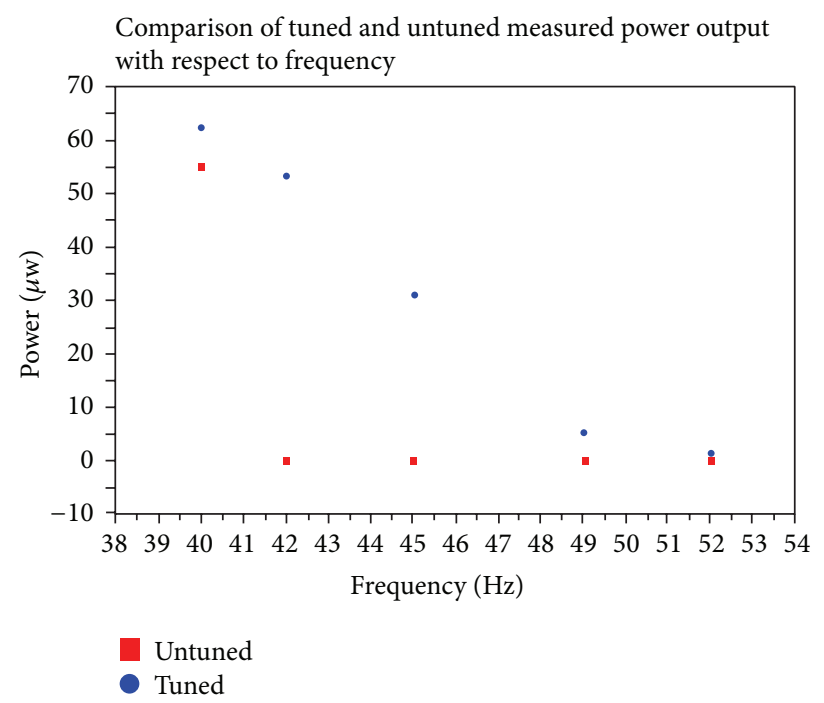

Figure 17: Tuned versus untuned power output with respect to frequency [14].

\section{Conflict of Interests}

The authors declare that there is no conflict of interests regarding the publication of this paper.

\section{References}

[1] G. Park, T. Rosing, M. Todd, C. Farrar, and W. Hodgkiss, "Energy harvesting for structural health monitoring sensor networks," Journal of Infrastructure Systems, vol. 14, no. 1, pp. 64-79, 2008.

[2] W. Clark, J. Romeiko, D. Charnegie, G. Kusic, and C. Mo, "A case study in energy harvesting for powering a wireless measurement systems," in Proceedings of the International Workshop on Structural Health Monitoring (IWSHM '07), pp. 1765-1772, Stanford University, Stanford, Calif, USA, September 2007.

[3] S. Arms, C. Townsend, D. Churchill et al., "Energy harvesting, wireless, structural health monitoring and reporting system," in Proceedings of the 2nd Asia Pacific Workshop on SHM, Melboune, Australia, December 2008.

[4] L. Wang and F. G. Yuan, "Vibration energy harvesting by magnetostrictive material," Smart Materials and Structures, vol. 17, no. 4, Article ID 045009, 14 pages, 2008.

[5] T. V. Galchev, J. McCullagh, R. L. Peterson, and K. Najafi, "Harvesting traffic-induced vibrations for structural health monitoring of bridges," Journal of Micromechanics and Microengineering, vol. 21, no. 10, Article ID 104005, 13 pages, 2011.

[6] Z. Li, L. Zuo, J. Kuang, and G. Luhrs, "Energy-harvesting shock absorber with a mechanical motion rectifier," Smart Materials and Structures, vol. 22, no. 2, Article ID 025008, 10 pages, 2013.

[7] J. Sirohi and R. Mahadik, "Piezoelectric wind energy harvester for low-power sensors," Journal of Intelligent Material Systems and Structures, vol. 22, no. 18, pp. 2215-2228, 2011.

[8] N. Wu, Q. Wang, and X. Xie, "Wind energy harvesting with a piezoelectric harvester," Smart Materials and Structures, vol. 22, no. 9, Article ID 095023, 9 pages, 2013.

[9] F. Khameneifar, S. Arzanpour, and M. Moallem, "A piezoelectric energy harvester for rotary motion applications: design and experiments," IEEE/ASME Transactions on Mechatronics, vol. 18, no. 5, pp. 1527-1534, 2013.

[10] C. A. Nelson, S. R. Platt, S. E. Hansena, and M. Fateh, "Power harvesting for railroad track safety enhancement using vertical track displacement," in Active and Passive Smart Structures and Integrated Systems, vol. 7288 of Proceedings of the SPIE, p. 11, San Diego, Calif, USA, April 2009.

[11] B. Joyce, Development of an electromagnetic energy harvester for monitoring wind turbine blades [M.S. thesis], Virginia Polytechnic Institute and State University, 2011.

[12] M. R. Pearson, M. J. Eaton, R. Pullin, C. A. Featherston, and K. M. Holford, "Energy harvesting for aerospace structural health monitoring systems," Journal of Physics: Conference Series, vol. 382, no. 1, Article ID 012025, 2012.

[13] M. Rhimi and N. Lajnef, "Tunable energy harvesting from ambient vibrations in civil structures," Journal of Energy Engineering, vol. 138, no. 4, pp. 185-193, 2012.

[14] J. Davidson and C. Mo, "Piezoelectric energy harvesting with frequency tuning for ventilation system monitoring," International Journal of Engineering Science and Innovative Technology, vol. 2, no. 5, pp. 114-124, 2013.

[15] S. J. Roundy, Energy scavenging for wireless sensor nodes with a focus on vibration to electricity conversion [Ph.D. dissertation], Department of Mechanical Engineering, University of California, Berkeley, calif, USA, 2003.

[16] D. Dumas, F. Lani, T. Monnier, R. Smaili, and J. Loyer, "Damage detection in composite structures using autonomous wireless systems: simulation \& validation," Journal of Physics: Conference Series, vol. 305, no. 1, Article ID 012084, 2011.

[17] D. Dondi, G. Napoletano, A. Bertacchini, L. Larcher, and P. Pavan, "A WSN system powered by vibrations to improve safety of machinery with trailer," in Proceedings of the IEEE Conference on Sensors, pp. 28-31, Taipei, Taiwan, October 2012.

[18] T. Ueno and S. Yamada, "Performance of energy harvester using iron-gallium alloy in free vibration," IEEE Transactions on Magnetics, vol. 47, no. 10, pp. 2407-2409, 2011.

[19] M. Zucca and O. Bottauscio, "Hysteretic modeling of electrical micro-power generators based on Villari effect," IEEE Transactions on Magnetics, vol. 48, no. 11, pp. 3092-3095, 2012. 
[20] D. Davino, A. Giustiniani, C. Visone, and A. Adly, "Experimental analysis of vibrations damping due to magnetostrictive based energy harvesting," Journal of Applied Physics, vol. 109, no. 7, Article ID 07E509, 2011.

[21] A. Erturk, "Piezoelectric energy harvesting for civil infrastructure system applications: moving loads and surface strain fluctuations," Journal of Intelligent Material Systems and Structures, vol. 22, no. 17, pp. 1959-1973, 2011.

[22] M. Wischke, M. Masur, M. Kröner, and P. Woias, "Vibration harvesting in traffic tunnels to power wireless sensor nodes," Smart Materials and Structures, vol. 20, no. 8, Article ID 085014, 8 pages, 2011.

[23] H.-J. Jung, I.-H. Kim, and J. Park, "Experimental validation of energy harvesting device for civil engineering applications," in Sensors and Smart Structures Technologies for Civil, Mechanical, and Aerospace Systems, vol. 8345 of Proceedings of the SPIE, p. 4, San Diego, Calif, USA, April 2012.

[24] I.-H. Kim, S.-J. Jang, and H.-J. Jung, "Performance enhancement of a rotational energy harvester utilizing wind-induced vibration of an inclined stay cable," Smart Materials and Structures, vol. 22, Article ID 075004, 7 pages, 2013.

[25] E. Sazonov, H. Li, D. Curry, and P. Pillay, "Self-powered sensors for monitoring of highway bridges," IEEE Sensors Journal, vol. 9, no. 11, pp. 1422-1429, 2009.

[26] J. Wardlaw, I. Karaman, and A. Karsilayan, "Low power circuits and energy harvesting for structural health monitoring of bridges," IEEE Sensors Journal, vol. 13, no. 2, pp. 709-722, 2013.

[27] M. Peigney and D. Siegert, "Piezoelectric energy harvesting from traffic-induced bridge vibrations," Smart Materials and Structures, vol. 22, no. 9, Article ID 095019, 11 pages, 2013.

[28] H. J. Xiang, J. J. Wang, Z. F. Shi, and Z. W. Zhang, "Theoretical analysis of piezoelectric energy harvesting from traffic induced deformation of pavements," Smart Materials and Structures, vol. 22, no. 9, Article ID 095024, 9 pages, 2013.

[29] K. Cunefare, E. Skow, A. Erturk, J. Savor, N. Verma, and M. Cacan, "Energy harvesting from hydraulic pressure fluctuations," Smart Materials and Structures, vol. 22, no. 2, Article ID 025036, 2013.

[30] C. Li and P. Tse, "Fabrication and testing of an energyharvesting hydraulic damper," Smart Materials and Structures, vol. 22, no. 6, Article ID 065024, 11 pages, 2013.

[31] Media Release, "Perpetuum wins contract to supply Southeastern Railways with energy harvester powred wireless sensor systems for 148 trains," June 2013, http://www.perpetuum.com/ news.asp.

[32] J.-W. Park, H.-J. Jung, H. Jo, and B. F. Spencer Jr., "Feasibility study of micro-wind turbines for powering wireless sensors on a cable-stayed bridge," Energies, vol. 5, no. 9, pp. 3450-3464, 2012.

[33] F. J. Xu, F. G. Yuan, J. Z. Hu, and Y. P. Qiu, "Design of a miniature wind turbine for powering wireless sensors," in Sensors and Smart Structures Technologies for Civil, Mechanical, and Aerospace Systems, vol. 7647 of Proceedings of the SPIE, San Diego, Calif, USA, April 2010.

[34] H.-J. Jung, S.-W. Lee, and D.-D. Jang, "Feasibility Study on a new energy harvesting electromagnetic device using aerodynamic instability," IEEE Transactions on Magnetics, vol. 45, no. 10, pp. 4376-4379, 2009.

[35] A. Abdelkefi, M. R. Hajj, and A. H. Nayfeh, "Piezoelectric energy harvesting from transverse galloping of bluff bodies," Smart Materials and Structures, vol. 22, no. 1, Article ID 015014, 11 pages, 2013.
[36] A. Abdelkefi, M. R. Hajj, and A. H. Nayfeh, "Modeling and analysis of piezoaeroelastic energy harvesters," Nonlinear Dynamics, vol. 67, no. 2, pp. 925-939, 2012.

[37] A. Abdelkefi, M. R. Hajj, and A. H. Nayfeh, "Design of piezoaeroelastic energy harvesters," Nonlinear Dynamics, vol. 68, no. 4, pp. 519-530, 2012.

[38] A. Abdelkefi, M. R. Hajj, and A. H. Nayfeh, "Enhancement of power harvesting from piezoaeroelastic systems," Nonlinear Dynamics, vol. 68, no. 4, pp. 531-541, 2012.

[39] A. Abdelkefi, M. R. Hajj, and A. H. Nayfeh, "Sensitivity analysis of piezoaeroelastic energy harvesters," Journal of Intelligent Material Systems and Structures, vol. 23, no. 13, pp. 1523-1531, 2012.

[40] S.-D. Kwon, "A T-shaped piezoelectric cantilever for fluid energy harvesting," Applied Physics Letters, vol. 97, no. 16, Article ID 164102, 2010.

[41] Q. Wang, Y. Zhang, N. X. Sun, J. G. McDaniel, and M. L. Wang, "High power density energy harvester with high permeability magnetic material embedded in a rotating wheel," in Nondestructive Characterization for Composite Materials, Aerospace Engineering, Civil Infrastructure, and Homeland Security, vol. 8347 of Proceedings of the SPIE, p. 6, April 2012.

[42] K. J. Phillips, C. A. Nelson, and M. Fateh, "Simulation and control system of a power harvesting device for railroad track health monitoring," in Health Monitoring of Structural and Biological Systems, Proceedings of the SPIE, p. 10, San Diego, Calif, USA, March 2011.

[43] T. Becker, M. Kluge, J. Schalk et al., "Autonomous sensor nodes for aircraft structural health monitoring," IEEE Sensors Journal, vol. 9, no. 11, pp. 1589-1595, 2009.

[44] D. Samson, T. Otterpohl, M. Kluge, U. Schmid, and T. Becker, "Aircraft-specific thermoelectric generator module," Journal of Electronic Materials, vol. 39, no. 9, pp. 2092-2095, 2010.

[45] D. Samson, M. Kluge, T. Becker, and U. Schmid, "Wireless sensor node powered by aircraft specific thermoelectric energy harvesting," Sensors and Actuators A: Physical, vol. 172, no. 1, pp. 240-244, 2011.

[46] "MPG-D655 Thin Film Thermogenerator Preliminary Datasheet," Accessed January 2014, http://micropelt.com/ downloads/datasheet_mpg_d655.pdf.

[47] M. Hassan, S.-H. Man, C. Z. Ng, A. Bermak, and C.-C. Chang, "Development of energy harvested wireless sensing node for structural health monitoring," in Proceedings of the 18th IEEE International Mixed-Signals, Sensors and Systems Test Workshop (IMS3TW '12), pp. 22-27, May 2012.

[48] S. Inamdar, Design of a solar energy harvesting system for structural health monitoring systems [M.S. thesis], The University of Texas, Austin, Tex, USA, 2012.

[49] T. Miller and B. F. Spencer Jr., "Solar energy harvesting and software enhancements for autonomous wireless smrt networks," NSEL Report Series UILU-ENG-2010-1802, University of Illinois, Champaign, Ill, USA, 2009.

[50] S. Jang, H. Jo, S. Cho et al., "Structural health monitoring of a cable-stayed bridge using smart sensor technology: deployment and evaluation," Smart Structures and Systems, vol. 6, no. 5-6, pp. 439-459, 2010.

[51] V. F. Godínez-Azcuaga, J. Farmer, P. H. Ziehl, V. Giurgiutiu, A. Nanni, and D. J. Inman, "Status in the development of selfpowered wireless sensor node for structural health monitoring and prognosis," in Nondestructive Characterization for Composite Materials, Aerospace Engineering, Civil Infrastructure, and 
Homeland Security, vol. 8347 of Proceedings of the SPIE, p. 6, San Diego, Calif, USA, April 2012.

[52] K. M. Farinholt, N. Miller, W. Sifuentes, J. MacDonald, G. Park, and C. R. Farrar, "Energy harvesting and wireless energy transmission for embedded SHM sensor nodes," Structural Health Monitoring, vol. 9, no. 3, pp. 269-280, 2010.

[53] B. Koser and H. Marinkovic, "Demonstration of wide bandwidth energy harvesting from vibrations," Smart Materials and Structures, vol. 21, no. 6, Article ID 065006, 2012.

[54] W. Al-Ashtari, M. Hunstig, T. Hemsel, and W. Sextro, "Frequency tuning of piezoelectric energy harvesters by magnetic force," Smart Materials and Structures, vol. 21, no. 3, Article ID 035019, 2012.

[55] S. P. Beeby, L. Wang, D. Zhu et al., "A comparison of power output from linear and nonlinear kinetic energy harvesters using real vibration data," Smart Materials and Strctures, vol. 22, no. 7, Article ID 075022, 15 pages, 2013.

[56] A. Erturk, J. Hoffmann, and D. J. Inman, "A piezomagnetoelastic structure for broadband vibration energy harvesting," Applied Physics Letters, vol. 94, no. 25, Article ID 254102, 2009.

[57] J.-T. Lin, B. Lee, and B. Alphenaar, "The magnetic coupling of a piezoelectric cantilever for enhanced energy harvesting efficiency," Smart Materials and Structures, vol. 19, no. 4, Article ID 045012, 7 pages, 2010.

[58] A. M. Wickenheiser and E. Garcia, "Broadband vibrationbased energy harvesting improvement through frequency upconversion by magnetic excitation," Smart Materials and Structures, vol. 19, no. 6, Article ID 065020, 11 pages, 2010.

[59] L. Liu and F. G. Yuan, "Nonlinear vibration energy harvester using diamagnetic levitation," Applied Physics Letters, vol. 98, no. 20, Article ID 203507, 2011.

[60] D. A. W. Barton, S. G. Burrow, and L. R. Clare, "Energy harvesting from vibrations with a nonlinear oscillator," Journal of Vibration and Acoustics, vol. 132, no. 2, Article ID 021009, 7 pages, 2010.

[61] F. Cottone, L. Gammaitoni, H. Vocca, M. Ferrari, and V. Ferrari, "Piezoelectric buckled beams for random vibration energy harvesting," Smart Materials and Structures, vol. 21, no. 3, Article ID 035021, 2012. 

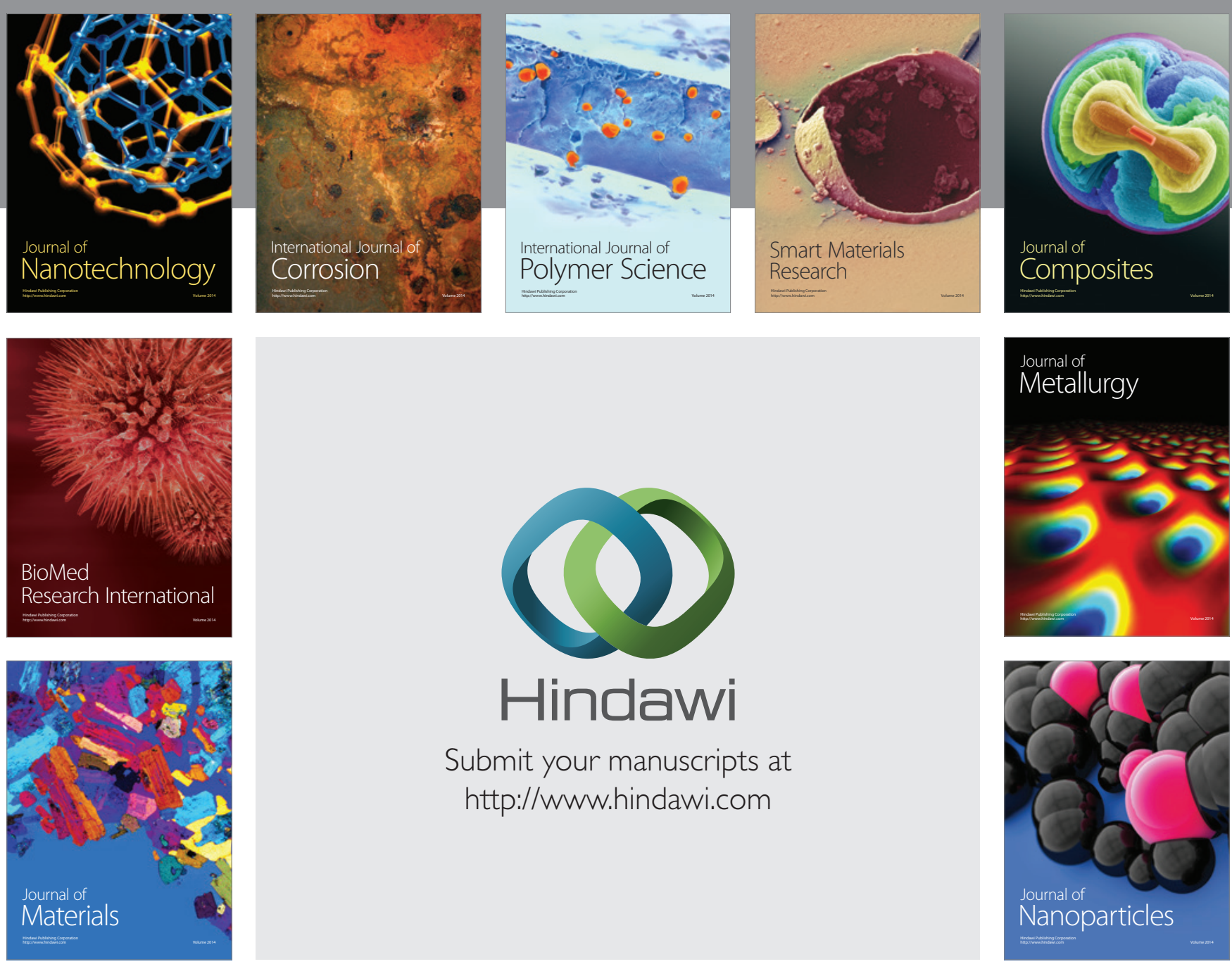

Submit your manuscripts at http://www.hindawi.com
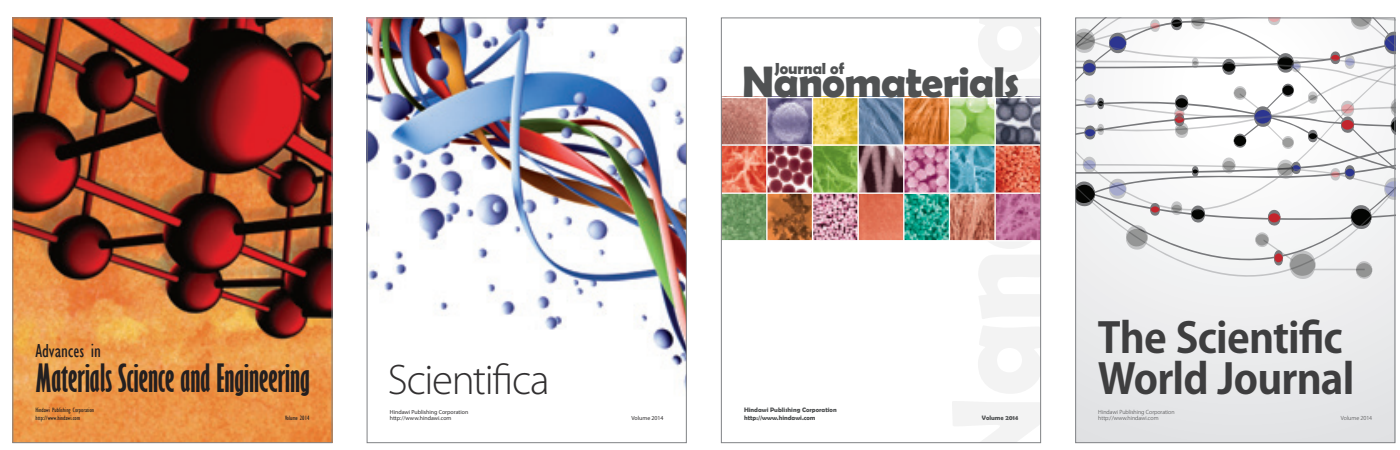

\section{The Scientific World Journal}
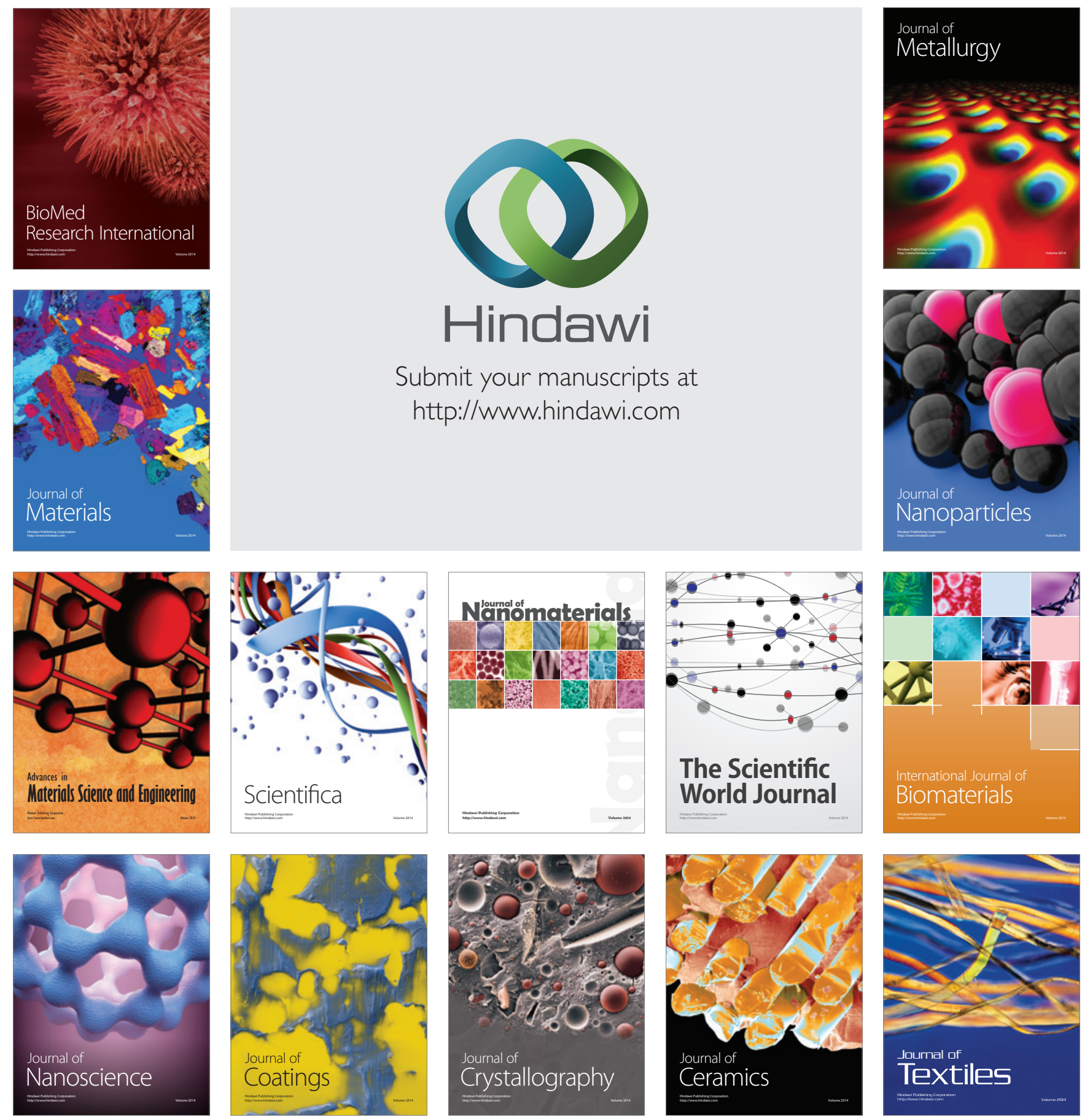